Int. J. Dev. Biol. 52: 413-414 (2008)

doi: $10.1387 / \mathrm{ijdb} .082697 \mathrm{gk}$

\title{
Dream big! \\ - a tribute to David L. Garbers (1944-2006)
}

\author{
GREGORY S. KOPF ${ }^{*}, 1$ and TIMOTHY A. QUILL 2 \\ ${ }^{1}$ Kansas University Medical Center Research Institute, Kansas City, Kansas, USA and ${ }^{2}$ Cecil H. and Ida Green Center for Reproductive, \\ Biology Sciences and the Department of Pharmacology, University of Texas Southwestern Medical Center, Dallas, Texas, USA
}

The field of reproductive biology lost a leader of immense stature on September 5, 2006 and the scientific community lost a passionate, creative and humble scientist that same day. Dave Garbers has been and will continue to be, remembered by all who were touched by him - family, friends and scientific colleagues. The two of us are very fortunate to have known Dave as a friend, mentor and colleague and are honored to write this tribute to him.

We begin by recollecting an experience that one of us (GSK) had many years ago as a young graduate student at Vanderbilt University School of Medicine. One morning upon entering Joel Hardman's laboratory in the Department of Physiology, Dave, then a postdoctoral fellow, was seen busily pipetting samples over Dowex columns. The columns were arranged in groups of ten and there had to be at least five or six groups neatly arranged along several bench tops. Dave was in constant motion adding samples to the columns, continually filling them and then collecting specific volumes of effluent into containers that would eventually be lyophilized and assayed. That evening, upon returning to study in the departmental library, Dave was seen standing at the same bench top, columns gone and now running several differently timed enzymatic assays using Lang-Levy mouth pipets - no Pipettemen back then! It was as if he never left the bench and was on to something new and different. The fact is, the laboratory was like home to Dave and the words that describe him in the laboratory - intense, focused, passionate, curious, open-minded, imaginative and big picture - describe his scientific career. They were also the words Dave used to convey to his trainees the qualities needed to be successful in science. We are both very fortunate to have worked with Dave and to have learned the many lessons he taught us that we have carried with us in our careers.

Dave's interest in reproductive biology was ignited early in his career, perhaps even while growing up on his parents' farm in La Crosse, Wisconsin. He attended the University of Wisconsin, Madison where he graduated with a B.S. in animal science in 1966, an M.S. in reproductive biology in 1970 and a Ph.D. in biochemistry in 1972. His first publications as an M.S. student with Neal First focused on the effects of a nonsteroidal inhibitor of gonadotrophic activity (ICl 33828) on ovarian and pituitary func- tion, as well as appetite and milk production, in various farm animals and rodents. While a Ph.D. student with Henry A. Lardy, Dave initiated aseries of studies that would become classic papers in the field of sperm biology. It was in these studies that Dave established the role for CAMP in regulating several aspects of sperm function, an area that his lab would pursue for many years to come. He once remarked that the introduction to his dissertation was very short since there was no literature in the field to review and summarize! Such was the pioneering spirit of Dave's scientific curiosity. While a postdoctoral fellow with Earl Sutherland and Joel Hardman at Vanderbilt, Dave continued his interest in cyclic nucleotide signaling by examining both adenylyl and guanylyl cyclases from several different tissues, applying his outstanding knowledge of enzymology to further understand the regulatory mechanisms of these important regulatory proteins. During this pursuit, however, Dave never wandered far from his love of reproductive biology. It was his return to fertilization biology that would ultimately lead his laboratory to significant findings, not only in this field but also in the fields of ophthalmology, gastroenterology and cardiology, thus defining his broad impact in the biomedical sciences.

Turning to the study of fertilization in the sea urchin, a model organism that provided huge quantities of gametes, Dave and his laboratory embarked on a series of landmark studies that would ultimately define a major part of his career. Building on observations made nearly a century earlier that sea urchin sperm alter their motility, metabolism and morphological characteristics in the vicinity of eggs, Dave demonstrated that sea urchin eggs secrete factors that cause striking changes in both sperm cAMP and cGMP metabolism. These factors, a large molecular weight fucose-sulfate glycoconjugate and a small peptide named speract, were ultimately purified and their individual roles in sperm-egg communication characterized. Dave and his colleagues demonstrated that speract and other egg peptides with different amino acid sequences isolated from divergent species only activated conspecific sperm, thus facilitating species-specific fertilization in the ocean. His group, together with the Vacquier and Brokaw laboratories, was first to identify a chemically defined sperm

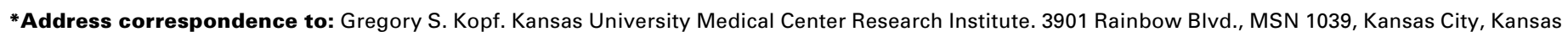
66160, USA. Tel. +1-913-945-6636. e mail: gkopf@kumc.edu
}

Published online: 4 July 2008

0214-6282/2008/\$35.00

(c) UBC Press

Printed in Spain 
chemoattractant, the egg peptide resact. Work with the Vacquier lab demonstrated that a sperm membrane-bound form of guanylyl cyclase was a likely target for the egg peptides and subsequent work by Dave's laboratory established that the guanylyl cyclase was indeed the peptide receptor. Cloning of this receptor guanylyl cyclase revealed a unique extracellular ligand binding domain that is divergent across species, a single transmembrane spanning region and intracellular protein kinase and cyclase domains that are highly conserved across species. The further demonstration by Dave's laboratory of the importance of the intracellular kinase domain for transmembrane signaling and an ATP requirement for hormone induced cGMP production is analogous to the GTP requirement for hormone-induced adenylyl cyclase production of cAMP.

This observation heralded a new way of thinking about how guanylyl cyclases functioned and demonstrated for the first time that this family of effector enzymes could function as cell surface receptors that generated their own low molecular weight second messengers. This insight provided the impetus for Dave to explore the nature of additional members of the guanylyl cyclase family in a variety of mammalian tissues. His laboratory demonstrated that other members of the membrane-bound guanylyl cyclase family functioned as receptors for atrial natriuretic peptides and heat stable bacterial enterotoxins, thus defining new signaling mechanisms in blood pressure regulation and the onset of secretory diarrhea, respectively. Another subgroup of this family, with important roles in sensory perception, was identified by Dave's laboratory as present in the mammalian retina and olfactory neuroepithelium. These discoveries highlight Dave's broad scientific curiosity and his desire to address fundamental biological questions using an array of animal models to study various physiological processes.

Despite these forays into other areas of biomedical research, Dave always returned to his love of fertilization biology. By the early 1990's, it was apparent from the research on sea urchin sperm cell signaling that a strategy of "walking up the phyla" would not successfully identify the corresponding primary sperm cell signaling components important to mammalian fertilization. As a result, Dave's research returned to mammalian spermatozoa. Characteristically, he started by tackling a fundamentally important and controversial topic in the field, i.e. the identification of species-specific sperm cell receptors and/or binding proteins for the egg's extracellular matrix. This led to the discovery of zonadhesin, an intriguing membrane protein with species-dependent differences in protein domain organization implicated in species-specific binding to the zona pellucida.

Around this time, Dave was also pondering another particularly difficult problem unique to mammalian spermatozoa. In essence, given that mammalian sperm cell samples behave as an asynchronous population where only a small percentage of cells respond to an external signal at a particular moment, how could one identify the molecular components involved in cellular signaling, particularly those most proximal to the initial sensory event? Ultimately, Dave embraced a discovery-based approach to identify sperm-specific membrane proteins likely to play important roles in sperm cell behavioral responses and fertilization. This decision reflected a hallmark of Dave's scientific style, namely quickly adopting new scientific techniques and incorporating new data to facilitate progress. For this project, he combined the signal peptide trapping technique with the rapidly expanding GenBank DNA sequence databases. A number of new sperm-specific membrane proteins were discovered using this approach. Among them, CatSper2 (a unique calcium ion channel) and sNHE (an apparent sodium-proton exchanger) proved essential to sperm motility regulation and male fertility. In addition, these studies suggested the existence of perhaps a few hundred sperm-specific membrane proteins leading Dave to expand this search using microarray expression profiling technology. The startling finding in this study was that a substantial proportion of the mammalian genome (2200 genes) appeared to be dedicated solely to production of sperm cells. Future research will likely demonstrate the potential utility of many of these sperm-specific proteins both as underlying causes of many idiopathic cases of male factor infertility and as targets for contraceptive development with reduced risks of side effects.

This brief retrospective of Dave's career demonstrates his impressive contributions to our understanding of the molecular basis of fertilization. Yet, as noted above, he made substantial contributions in other research areas including hypertension, tissue remodeling and most recently the genetic manipulation of spermatogonial stem cells - all fields with tremendous implications for medicine and biology. Future studies that will evolve from his research on sperm cells, as well as from other research areas summarized by authors in this volume, will undoubtedly yield valuable insights into the amazing process of fertilization. In time, with persistence and political resolve, perhaps some of Dave's goals of developing new male contraceptives, species-specific contraceptives and enhanced fertility of both agriculturally important animals and endangered species can be achieved. This is yet another hallmark of Dave's legacy - "dream big". 